\title{
LAS OBSERVACIONES SOBRE LAS BELLAS ARTES (1790-1791) DE ISIDORO BOSARTE: LA HISTORIA DEL ARTE COMO HISTORIA DE LA CIVILIZACIÓN DURANTE LAS LUCES*
}

\author{
Daniel Crespo Delgado ${ }^{1}$ \\ Universidad Complutense de Madrid
}

\begin{abstract}
Las Observaciones sobre las bellas artes entre los antiguos (1790-1791) de Isidoro Bosarte es una de las publicaciones sobre historia del arte más olvidadas del siglo XVIII. En este artículo se analizan algunos de sus contenidos y se proporcionan datos inéditos sobre su autor, cuya trayectoria es igualmente poco conocida. Sin embargo, el principal interés de las Observaciones reside en el contexto en el que se crearon y se presentaron al público. Escritas y leídas en la cátedra de historia literaria de la biblioteca de los Reales Estudios de Madrid, pueden ser consideradas una de las primeras conferencias públicas sobre historia del arte en España.
\end{abstract}

Palabras clave: Isidoro Bosarte; antigüedad; historiografía artística de la ilustración; cátedra de historia literaria.

\section{ISIDORO BOSARTE'S OBSERVACIONES SOBRE LAS BELLAS ARTES (1790-1791): ART HISTORY AS HISTORY OF CIVILIZATION DURING THE ENLIGHTENMENT}

The book Observaciones sobre las bellas artes entre los antiguos (1790-1792) has been overlooked by historiography, as has its author, Isidoro Bosarte. This study offers new information about his life and professional trajectory, and it analyzes the contents of his important but neglected work. The main interest of the Observaciones is the context of production and its public reception. Written and presented orally in the "Cátedra de Historia Literaria" of the Royal Studies of Madrid, this text can be considered one of the first public Art History conferences in Spain.

Key words: Isidoro Bosarte; Antiquity; art historiography of the Enlightenment; Cátedra de Historia Literaria.

Cómo citar este artículo / Citation: Crespo Delgado, Daniel (2021) "Las observaciones sobre las bellas artes (1790-1791) de Isidoro Bosarte: la historia del arte como historia de la civilización durante las Luces”. En: Archivo Español de Arte, vol. 94, núm. 375, Madrid, pp. 247-260. https://doi.org/10.3989/aearte.2021.15.

Las Observaciones sobre las bellas artes entre los antiguos (1790-1791) es una de las publicaciones sobre historia del arte peor conocidas del siglo XVIII [fig. 1]. En este olvido ha influido seguramente la escasa atención que en líneas generales ha despertado su autor. No obstante, Isidoro Bosarte es una de las principales figuras de la historiografía artística española de la Ilustración. Las Observaciones también son notables: compuestas por cuatro libros donde se analizan los monumentos de la antigua Grecia y Egipto, es la publicación original española más extensa del siglo XVIII sobre las artes en la Antigüedad. Como solía ser habitual en este tipo de trabajos, las

\footnotetext{
* Este trabajo se ha desarrollado en el marco del Proyecto de Investigación I+D "La creación de un nuevo relato: críticos e historiadores del arte (1772-1838). Escritos e imágenes”, ref. PID2019-107170GB-I00, financiado por el Ministerio de Ciencia e Innovación.

1 daniecre@ucm.es / ORCID iD: https://orcid.org/0000-0002-1493-4651
} 


\title{
OBSERVACIONES
}

\section{SOBRE LAS BELLAS ARTES}

\author{
BNTRB LOS ANTIGUOS
}

\author{
IASTA IA CONQUISTA DE GRECTA
}

POR LOS ROMANOS.

Asunto propuesto en la Cátedra de Historia Literaria de los Reales Estudios de Madrid al concluirse el primer afio del Curso Académico.

\section{PARTE TERCERA.}

\section{Contiene las observaciones sobre la Arquitec- tura entre los Griegos.}

\section{E I D A}

POR DON ISIDOROBOSARTE El dia 28 de Junio de 1790.

Insequar ingressus antiquitatis rerum natur $\alpha, \mathbb{B}$ eorum, qui ..... inventiones perquisitas Scriptorum praceptis dedicaverunt. Vitruv. præfat. Libr. II.

\section{MA D R I D:}

\section{en ra Oficina de Don Bexizo Cano. $M D C C X C L$.}

Fig. 1. Isidoro Bosarte, Observaciones sobre las bellas artes entre los antiguos... Parte Tercera, Madrid, Benito Cano, 1791.

categorías desde las que se explican las obras antiguas y se aborda su evolución suponen un revelador punto de vista para entender la concepción contemporánea de las artes. De hecho, Bosarte incluyó interesantes reflexiones sobre la situación de estas disciplinas en España, los motivos de su predicada decadencia y los caminos que podían tomarse para lo que él consideró su restauración.

Pero más allá de la relevancia de su autor y de sus contenidos, uno de los rasgos que creo más llamativos de las Observaciones es el contexto en el que se realizaron. Bosarte las escribió como una serie de lecciones para ser leídas públicamente en la cátedra de historia literaria de los 
Reales Estudios de Madrid. A lo largo del siglo XVIII, las academias de bellas artes organizaron actos abiertos al público en los que se leyeron oraciones sobre las artes. La Real Academia de San Fernando, por ejemplo, lo hizo desde su creación en 1757. Sin embargo, las Observaciones de Bosarte se presentaron en un marco no vinculado a la profesión artística, pues la cátedra de historia literaria tenía como objetivo exponer la historia del conocimiento. Que unas conferencias centradas en las bellas artes se leyesen en un curso que perseguía explicar el desarrollo del saber humano, revela la consideración de lo artístico durante las Luces, su consolidación como un rasgo característico de la historia y de la denominada civilización, es decir, como parte del canon cultural que promocionó la Ilustración.

\section{Un escenario singular: la cátedra de historia literaria}

Bosarte leyó las Observaciones sobre las bellas artes entre los antiguos por vez primera en cuatro sesiones los días 29 de mayo, 15 y 28 de junio y 13 de julio de 1790 en la biblioteca de los Reales Estudios de San Isidro de Madrid. ${ }^{2}$ Como acabo de apuntar, no fue una lectura aislada y casual, sino que se llevó a cabo en un marco preciso: la cátedra de historia literaria. Tras la expulsión de los jesuitas (1767), el Colegio Imperial de Madrid pasó a depender de la Corona, cambió su nombre por el de Reales Estudios y albergó una serie de nuevas cátedras entre las que destacó, precisamente, la de una materia cuya enseñanza era inédita en España e incluso en Europa. ${ }^{3}$ La historia literaria empezó a impartirse en enero de 1789 y su responsable, Miguel de Manuel, afirmó que su finalidad era el estudio de las diferentes etapas o "edades de la literatura" que se dijo se habían sucedido a lo largo de la historia. ${ }^{4}$ Cabe advertir que en este momento por literatura no se entendía únicamente la creación literaria, sino todo saber expresado mediante la escritura, comprendiendo "todos los conocimientos humanos". ${ }^{5}$ Por tanto, esta cátedra iba mucho más allá de lo que hoy conocemos como historia de la literatura.

Las clases de la cátedra eran de unas dos horas y se impartían en la biblioteca de San Isidro un día o dos a la semana. ${ }^{6}$ Consistían en la lectura de un fragmento del libro de Juan Andrés Dell'origine, progressi e stato attuale d'ogni letteratura (1782-1799), traducido al español en diez tomos entre 1784 y 1806, siendo comentado por el bibliotecario primero de los Reales Estudios. Hasta su fallecimiento en 1798, Miguel de Manuel ocupó este puesto y por tanto se encargó de la enseñanza durante la mayor parte de la existencia de la cátedra. El último periodo en el que hay constancia que se impartió fue en 1799 y $1800 .^{7}$ Su programa varió. En un inicio se plantearon tres cursos anuales que empezarían en enero: en el primero se estudiaría la literatura de Grecia, Roma y las naciones "bárbaras" (por tales se entendió la de China, Persia, India, la árabe antigua, la egipcia, la celta, la etrusca... $)^{8}$; en el segundo, la literatura desde su considerado renacimiento hasta el presente; en el tercero, la española "en todas sus épocas". ${ }^{9}$ Ya en 1790 parece que se decidió cambiar este programa. El primer año permanecería igual, pero el segundo abordaría la literatura

\footnotetext{
2 Bosarte, 1790-1791.

${ }^{3}$ Si bien la documentación de archivo y la prensa me ha permitido dar con noticias inéditas sobre la cátedra y la biblioteca, destaco la siguiente bibliografía: Simón, 1992; Miguel, 1992; Santiáñez, 2007.

${ }^{4}$ Memorial Literario, febrero de 1789: 202-203; Exercicios, 1790: prólogo, s.p.

${ }^{5}$ Urzainqui, 1987.

${ }^{6}$ De las diversas noticias se deduce que fue así en términos generales. No obstante, en junio de 1792 Manuel escribió que leía un discurso cada ocho días y lo discutía "sin limitaciones de tiempo". Archivo Histórico Nacional, Madrid (AHN), Jesuitas, 744-1. En enero de 1800, José de Villarroel, sustituto de Manuel, propuso un nuevo sistema de enseñanza con lecciones diarias de una hora y un nuevo libro de texto. No obstante, Villarroel dimitió de su puesto en otoño de ese mismo año. AHN, Jesuitas, 751-2.

7 AHN, Jesuitas, 751-2; Diario de Madrid, 27 de septiembre de 1800. Tras la muerte de Manuel (también recogida en la prensa: Diario de Madrid, 20 de septiembre de 1798), en el Mercurio de España de diciembre de 1798 apareció una noticia en la que el Ministro del Interior instaba a los bibliotecarios a retomar la enseñanza.

${ }^{8}$ Trigueros, 1790?: 52.

9 Mercurio de España, mayo de 1789: 91.
} 
sagrada (la católica canónica), el tercero la medieval y árabe, y el cuarto "la restauración de las letras en los últimos siglos y del actual estado de la literatura en las naciones cultas". ${ }^{10}$

Al margen de sus cambios, resulta claro que los cursos de dicha cátedra pretendían ofrecer un recorrido crítico por la historia del conocimiento humano. Esto suponía una toma de posición ideológica, puesto que se debían señalar las materias, las naciones, las tradiciones, los autores y los libros que se consideraban más adelantados, los juzgados modélicos, y los que se veían como atrasados. De ahí que Manuel dijese que la cátedra de historia literaria acostumbraba a sus asistentes a "pensar bien", es decir, en una dirección y sentido precisos. ${ }^{11}$ No hay duda de que proporcionaba referencias muy completas para definir el sistema de saber defendido. Las categorías de comprensión (y exclusión para lo que quedaba al margen) que aportaba eran exhaustivas, al determinar lo que era conocimiento, ordenarlo y jerarquizarlo. En todos los escritos vinculados a la cátedra se insistió en que un objetivo ineludible era individualizar las causas que estimulaban el desarrollo y la plenitud de la literatura, y aquellas que significaban su decadencia. El bibliotecario segundo Cándido María Trigueros insistió en que la historia literaria no podía reducirse a una biblioteca, a una mera acumulación de libros; ${ }^{12}$ debía aspirar a trazar una detallada cartografía de lo que se consideraba cultura o civilización, de las disciplinas que la conformaban y de los resortes que la hacían evolucionar. Todo ello desde principios concretos, que no eran otros que los de la Ilustración a la que pertenecían sus impulsores. De hecho, la historia literaria supone un privilegiado retrato de la visión del conocimiento por parte de las Luces. La dependencia del poder de los Reales Estudios de San Isidro condicionó la aproximación de la cátedra, que las tintas usadas en el paisaje del saber que proporcionó no pudiesen ser radicales. Los planteamientos de Juan Andrés en el Origen, progresos y estado actual de toda la literatura eran moderados, alejados de los "espíritus fuertes", pero también del pensamiento más reacio a las novedades. ${ }^{13}$

Las Observaciones sobre las bellas artes entre los antiguos de Bosarte no formaron parte del curso ordinario de la cátedra de historia literaria. Según el testimonio de Miguel de Manuel, el éxito del primer curso impartido en 1789, le llevó a proponer en enero de 1790 que los asistentes que lo deseasen preparasen una disertación para leerla sobre una materia "amena", "instructiva" y que no se hubiese podido "analizar adecuadamente en los discursos leídos en la cátedra" ${ }^{14}$ Esta lectura de conferencias por parte de alumnos y colaboradores continuó en los años siguientes. Conservamos por ejemplo la que en 1794, cuando la cátedra había pasado ya su breve periodo de esplendor, presentó el médico Joaquín Villalba sobre las aguas naturales y medicinales que se bebían en Hispania. ${ }^{15}$ En un informe de 1793, el director de los Reales Estudios, Estanislao de Lugo, apuntó que en la cátedra se leían frecuentemente disertaciones que llevaban algunos concurrentes "sobre los asuntos de que han querido encargarse". ${ }^{16}$

Al igual que un nutrido grupo de compañeros - unos diez-, Isidoro Bosarte decidió escribir y presentar una disertación. La leyó en la cátedra entre mayo y julio de 1790. Al menos José Cornide también leyó la suya, dedicada a la historia natural antes de Plinio, en este periodo (en su caso el 12 de junio). ${ }^{17}$ Pero esta no fue la única lectura pública de las Observaciones.

Como un recurso más para difundir las enseñanzas de la cátedra, Miguel de Manuel organizó los días 23, 24 y 25 de setiembre del mismo 1790 unos Ejercicios públicos para exponer dichas disertaciones a la concurrencia que libremente desease acudir a los Reales Estudios. Un poco antes del evento, Manuel imprimió un texto bellamente editado donde recogió los discursos que

${ }^{10}$ Mercurio de España, diciembre de 1791: 349. En 1792, Manuel señaló que a los cuatro años de literatura universal le seguirían dos centrados en la española. AHN, Jesuitas, 744-1.

${ }_{11}$ Exercicios, 1790: prólogo, s.p.

12 Trigueros, 1790?: 12.

13 Scandellari, 2007.

${ }^{14}$ Exercicios, 1790: prólogo, s.p.; Trigueros, 1790?: 54-55.

15 Joaquín de Villalba, Discurso de las naturales, fuentes universales y toda suerte de baños, 1794. Biblioteca Nacional de España, Mss. 13339.

${ }_{16}$ AHN, Estado, 3182-87

${ }^{17}$ Cornide, 1791. 
se iban a leer, los autores y sus principales tesis. ${ }^{18}$ Junto a las ya citadas de Bosarte y Cornide, se discutieron las siguientes lecciones (recordemos que el primer curso se destinó a la literatura grecorromana y de las "naciones bárbaras"): la educación en "las naciones antiguas"; sus bibliotecas; sobre la utilidad de la "historia de los estudios antiguos"; el saber de "las antiguas naciones asiáticas y africanas"; la literatura europea hasta Augusto "exclusas Grecia y Roma"; los filósofos griegos antes de la Escuela de Alejandría; y sobre el influjo que las costumbres y la constitución política de los griegos tuvieron en su filosofía. ${ }^{19}$

Estas lecciones públicas se celebraron en 1790 y en 1791. En ambos años fueron defendidas por personajes de sólida formación y, en algunos casos, de considerable trayectoria intelectual a sus espaldas. Aunque en un principio la cátedra de historia literaria pudo pensarse como un complemento para la formación de los alumnos que asistían a las otras enseñanzas de los Reales Estudios, ${ }^{20}$ finalmente sus asistentes fueron "hombres hechos y estudiosos veteranos" ${ }^{21}$ En una petición para que los ejercicios públicos de la cátedra de historia literaria previstos en 1793 pudiesen dedicarse de nuevo al rey y fuesen presididos en su "Real nombre", Miguel de Manuel incidió en el distinto perfil de los concurrentes a su cátedra respecto a las otras de los Reales Estudios. A la de historia literaria no acudían "niños y jóvenes" sino "gentes ya instruidas". En el primer curso de 1789, lo hicieron personas "graduadas las más en facultades mayores, algunos catedráticos de estos mismos Reales Estudios y de las Universidades del Reino; otros eclesiásticos de probidad y ciencia; muchos conocidos de antemano por su erudición". Quienes habían presentado disertaciones (primero en el seno de la cátedra y luego en los ejercicios públicos) eran "sujetos algunos de los cuales estaban ya acreditados por su literatura". Manuel citó a Bosarte entre ellos. ${ }^{22}$

Pero el éxito de la cátedra no solo estuvo en reunir perfiles de alto nivel y de heterogéneas ocupaciones literarias, sino también en su número. Manuel se refirió al "concurso prodigioso" ya durante el primer curso de 1789. A los seis meses de iniciarse asistían continuamente 154 personas; acabando el año eran 168, si bien más adelante Manuel subió la cifra a casi doscientos. ${ }^{23}$ Este éxito se debió en parte a que la cátedra de historia literaria contó en sus primeros años de existencia con el apoyo de las autoridades, de manera especial con el del secretario de Estado, el conde de Floridablanca, quien incluso presidió los ejercicios públicos de 1791. Por tanto, ciertos literatos consideraron que participar en la cátedra podía ser un medio para promocionarse y hacerse un lugar en los círculos intelectuales y de posibles protectores. ${ }^{24}$ De hecho, cuando a principios de 1792 Floridablanca cayó del poder, la cátedra entró en decadencia. No ayudaron las pretensiones honoríficas, económicas y de control absoluto de Manuel de todo lo concerniente a la biblioteca, que le causaron bastantes enemigos. ${ }^{25}$ Los ejercicios públicos a celebrar en 1793 no pudieron dedicarse al rey ni ser presididos en su nombre, lo que provocó que no se realizasen de ahí en adelante. ${ }^{26} \mathrm{La}$ última publicación vinculada a la cátedra apareció en 1794, aunque esta relación, a diferencia de las aparecidas en los años anteriores, no se explicitó en ningún lugar del libro. ${ }^{27} \mathrm{La}$ falta de un amparo expreso de las más altas autoridades hizo que el prestigio de la enseñanza y las posibilidades de promoción para los literatos descendiese bruscamente. El progresivo colapso de la cátedra no pudo revertirse hasta su definitiva desaparición en $1802 .{ }^{28}$ El 7 de enero de 1798 se publicó una

${ }^{18}$ La impresión de los Exercicios de 1790 ascendió a la nada despreciable cifra de 3331 reales y 891 su encuadernación. AHN, Jesuitas, 744-1.

${ }^{19}$ Se analizan los contenidos de estas lecciones y sus autores en Romero, 2004.

${ }^{20}$ Así parece deducirse de un informe de 1785 de Messeguer y Manuel (Simón, 1992: 363-364).

${ }^{21}$ Trigueros, 1790?: 44.

${ }^{22}$ AHN, Estado, 3128-87. Véase igualmente el memorial de Manuel de 6 de noviembre de 1792 en AHN, Jesuitas, 751-2.

${ }^{23}$ Exercicios, 1790: prólogo, s.p.; Gazeta de Madrid, 1 de noviembre de 1790; AHN, Estado, 3182-87.

${ }^{24}$ Tanto Manuel como Estanislao de Lugo, director de los Reales Estudios, fueron de esta opinión: AHN, Jesuitas, 751-2; AHN, Consejos, 11281-42.

${ }^{25}$ Simón, 1992: 366-372; Miguel, 1992: 199, 206 y ss.; AHN, Jesuitas, 744-1.

26 AHN, Estado, 3128-87.

27 Aristófanes, 1794.

${ }^{28}$ Simón, 1992: 372. 
carta en el Diario de Madrid que denunciaba con tristeza la escasa asistencia a sus clases, apenas 12 personas, lo que contrastaba con la numerosa concurrencia del pasado.

Los ejercicios públicos también contaron con una nutrida asistencia. Abierto a todo el que desease asistir, el de 1790 congregó público "de todas clases". Fue presidido por el arzobispo de Toledo y otras autoridades políticas e intelectuales - las crónicas del evento destacan por ejemplo al duque de Almodóvar, que entre otras actividades culturales de primer rango, leyó en 1787 la oración pública en los actos trienales de la Academia de San Fernando-, alguno de los cuales discutieron hasta bien entrada la tarde con los ponentes. ${ }^{29} \mathrm{El}$ éxito de público todavía fue mayor en los ejercicios de 1791. Las noticias que se hicieron eco de su celebración subrayaron que asistieron más de 500 personas, presididas por el conde de Floridablanca, entre las que se contaban altos cargos, "sabios y literatos" o "damas de primera distinción". ${ }^{30} \mathrm{El}$ tono social de estos eventos se revelaría por ejemplo en las amargas quejas de Bosarte en mayo de 1791 denunciando su pésima situación económica. Al no tener dinero para un traje decente debía declinar participar en los ejercicios de $1791 .^{31}$

Por tanto, Bosarte leyó sus lecciones sobre el arte en Grecia y Egipto ante una numerosa y variada concurrencia. Podemos considerarlas una de las primeras conferencias públicas sobre historia del arte realizadas en España. No se pronunciaron en una academia de bellas artes, es decir, en una institución profesional y especializada en tales disciplinas. Esto ya es algo inédito. Pero, además, sus contenidos se centraron exclusivamente en el pasado monumental, en el análisis y caracterización de las producciones artísticas de un periodo histórico concreto.

A pesar de su novedad, estas lecciones de Bosarte ni extrañaron ni se vieron como una frivolidad por parte de los asistentes a la cátedra o por el público de los ejercicios. Al contrario, las fuentes manifiestan que fue una de las disertaciones que despertó mayor interés. Se deduce por ejemplo de una carta aparecida en la prensa del reputado escritor Esteban de Arteaga apoyando la cátedra y sus ejercicios públicos. ${ }^{32}$ Por otro lado, si bien Miguel de Manuel afirmó que las disertaciones de los concurrentes a la cátedra se irían imprimiendo, al final fueron las menos. ${ }^{33}$ En 1793, dio noticia de ellas y subrayó que se habían publicado "a su costa" o las había promovido si sus correspondientes autores las pudieron "imprimir por sí". Por uno u otro conducto se habían publicado la citada disertación de Cornide; un ensayo sobre la historia literaria de Cándido María Trigueros; el de la tragedia griega de Pedro Estala; el de las versiones arábigas de los clásicos griegos de Juan Antonio Romero; y el de Bosarte. ${ }^{34}$ El resumen del trabajo de Bosarte en esta noticia de 1793 es el que ocupa más espacio. Además, cabe advertir que si bien las restantes disertaciones se pudieron publicar en un único tomo cada una, la de Bosarte, más extensa, ocupó cuatro. Los costearía Manuel (pues la situación de su autor no permitía otra opción), apareciendo entre finales de 1790 y principios de 1791. La prensa contemporánea los anunció puntualmente. ${ }^{35}$ La conclusión de todo ello parece clara: se consideraron una de las aportaciones emblemáticas de la cátedra.

La lectura de las Observaciones de Bosarte en la cátedra de historia literaria de los Reales Estudios de San Isidro de Madrid, junto a disertaciones sobre filosofía, historia natural, bibliotecas o literatura relativas a su misma época histórica, ante un público diverso y formado, en un marco tan prestigioso y respetable, revela que las bellas artes eran un contenido asimilado a la civiliza-

${ }^{29}$ Mercurio de España, octubre de 1790: 527-530; Gazeta de Madrid, 1 de noviembre de 1790.

${ }^{30}$ Mercurio de España, diciembre de 1791: 347-350; Gazeta de Madrid, 23 de diciembre de 1791.

${ }^{31}$ A raíz de esta petición se le concedió una ayuda de costa y un sueldo mayor. AHN, Jesuitas, 744-1. De ahí —suponemos - su participación en los ejercicios de 1791 .

${ }^{32}$ Espíritu de los mejores diarios literarios que se publican en Europa, 13 de diciembre de 1790: 343-345.

${ }^{33}$ Exercicios, 1790: prólogo, s.p.

${ }^{34}$ Gazeta de Madrid, 2 de julio de 1793. En el mismo 1793 apareció el Discurso sobre las colecciones de cánones griegas y latinas de González Arnao, leído en los ejercicios de 1791, si bien fue publicado por la Imprenta Real. Posteriormente a 1793, la única disertación publicada fue la ya citada de Pedro Estala sobre la comedia antigua (ver nota 26). Al margen de que la maltrecha situación económica de Bosarte le impediría sufragar la impresión de las Observaciones, la documentación nos informa que las cedió a la cátedra para su publicación. AHN, Consejos, 5444-11.

${ }^{35}$ Mercurio de España, diciembre de 1790: 720; Diario de Madrid, 21 de marzo de 1791. Todavía se anunciaba su venta, a 3 reales, a principios del siglo XIX: Gazeta de Madrid, 16 de abril de 1802. 
ción según la definió la Ilustración y se incluían en el canon cultural que promocionaba. De ahí su perfecto encaje en espacios de sociabilidad literaria de las Luces como eran dicha cátedra y sus ejercicios públicos.

$\mathrm{Al}$ margen de las Observaciones, no hay constancia de que en la cátedra se leyese alguna otra disertación sobre bellas artes. En el manual de Juan Andrés, a pesar de las muchas disciplinas analizadas, no hubo ningún capítulo dedicado a estas materias. Sin embargo, en varios lugares de su tratado Andrés acudió a ellas para matizar o enriquecer alguno de sus argumentos sobre la situación del conocimiento de tal o cual nación o periodo. ${ }^{36}$ Sabemos por varios testimonios del interés de Andrés por las artes y la alta consideración que tenía de ellas como manifestación cultural. ${ }^{37}$ Es significativo que cuando quedaron vacantes plazas de bibliotecario de los Reales Estudios, algunos pretendientes incluyeron en su curriculo sus conocimientos - literarios - sobre bellas artes. Lo hizo Bosarte (que optó como veremos más adelante a las plazas de bibliotecario segundo y primero), pero también el escritor y periodista José Mariano Beristain o el dramaturgo Leandro Fernández de Moratín. ${ }^{38}$

No obstante, durante la Ilustración, las bellas artes y la civilización, esta última una palabra de creciente uso, no solo se encontraron en la cátedra de historia literaria. En otros trabajos ya me he detenido en los múltiples testimonios de la literatura artística española de las Luces afirmando que, en elocuente expresión de Jovellanos, "el origen y progresos de las bellas artes eran un indicio harto seguro de la cultura de los pueblos". ${ }^{39}$ En estas líneas me gustaría incidir en la cara inversa, es decir, en cómo lo artístico se integró en los relatos historiográficos; si se le otorgó ese lugar entre las manifestaciones culturales preminentes y, por consiguiente, en la historia. En especial si apareció y cómo lo hizo en los libros de historia antigua, aquellos que trataron la época analizada por Bosarte en las Observaciones.

Es de sobra conocido que el estudio de los monumentos de la Antigüedad motivó algunas de las publicaciones historiográfico-artísticas más renovadoras de la Ilustración como las de Caylus o, por descontado, Winckelmann. El propio Andrés dio noticia de estos trabajos en su historia literaria, elogiando lo que habían enriquecido el conocimiento del mundo antiguo y sus benéficos efectos sobre las bellas artes al presentar principios estéticos ejemplares. ${ }^{40}$ Pero también en las historias generales de la Antigüedad escritas en el siglo XVIII, en especial de la griega, se incluyeron referencias a las contribuciones artísticas. El prestigio de los monumentos y los artistas helénicos, ya ensalzados por las fuentes antiguas, hizo que fuese habitual citarlos en las historias que glosaban los alcances de esa idolatrada época. Las bellas artes se vieron como un argumento más que demostraba la presunta superioridad alcanzada por la cultura griega clásica; incluso podía arrojar más luz sobre las razones que motivaron dicho desarrollo. Al aparecer en estos libros generales, leídos por un público amplio, y además referidos a una época juzgada modélica, junto a hechos políticos o literarios venerados, la reputación de las artes se reforzó. La Antigüedad, por tanto, contribuyó de muy diversos modos al prestigio y a la creciente significación cultural predicada de las bellas artes a lo largo de la Edad Moderna.

En sus prolíficos años mallorquines, en los que estudió de manera novedosa los monumentos de Palma, tenemos constancia de que Jovellanos consultó la History of Ancient Greece, its Colonies and Conquests (1786) del escocés John Gillies. En sus diarios, Jovellanos dijo haber leído con especial gusto el capítulo de Gillies sobre las bellas artes, que se iniciaba precisamente destacando el interés del estudio de estas materias para ofrecer un discurso completo sobre la historia y la cultura de la antigua Grecia ${ }^{41}$ No obstante, también contamos con trabajos en español sobre dicha época donde las bellas artes tuvieron un lugar. En 1776, se tradujo la Historia de las Artes y

${ }^{36}$ En relación a la Antigüedad, por ejemplo, ver Andrés, 1784-1806: I, 26, 30-33 y 82.

${ }^{37}$ Me detengo en ello en un artículo que estoy preparando.

${ }^{38}$ AHN, Consejos, 5443-12bis y 5443-13. Los perfiles de los bibliotecarios de los Reales Estudios se analizan en Viñao, 1995.

${ }^{39}$ Entre otros en Crespo, 2012: 361-379 o 2016.

40 Andrés, 1784-1806: VI, 547-548.

${ }^{41}$ Crespo / Domenge, 2013: 51. 
Ciencias de Charles Rollin que, dirigida no a los eruditos sino al "común de los lectores", incluyó las bellas artes en esta autodefinida "historia del entendimiento humano". El historiador francés dedicó una serie de capítulos a la arquitectura, la pintura y la escultura, pues tal era la restringida y canónica nómina de las bellas artes en el siglo XVIII. ${ }^{42}$ En ellos destacó la que dijo determinante aportación de los griegos en los respectivos orígenes de estas disciplinas y en su perfección. De hecho, en su Historia de las Artes y Ciencias de los Antiguos, también publicada en español en 1776, Rollin volvió a abordar las contribuciones griegas a las bellas artes. En ambas obras afirmó que su excelencia coincidía históricamente con la de las ciencias y otras artes, tal y como parecían demostrar periodos áureos de la civilización como la época de Pericles, Augusto o Luis XIV (esta coincidencia con figuras políticas no resulta casual), pues "el discernimiento de la perfección es el mismo en todo lo que depende del ingenio". ${ }^{43}$

Entre 1793 y 1795 aparecieron en español los cuatro tomos de la Historia política y literaria de Grecia del italiano Carlos Denina. Sus suscriptores eran muy variados, encontrándose incluso arquitectos de renombre como Juan de Villanueva, Pedro Arnal o Vicente Gascó. Este interés tal vez vino motivado porque desde el prólogo de su obra Denina ya aclaró que iba a tratar sobre las bellas artes en su fresco de la Hélade, que quiso completo, que no se redujese a una mera historia política y bélica sino que expusiese las aportaciones de los griegos en todos los ámbitos. ${ }^{44} \mathrm{Y}$ lo hizo, puesto que fue introduciendo epígrafes sobre las bellas artes en los distintos periodos en los que dividió el pasado de la antigua Grecia, intentando mostrar su situación a la luz de la evolución del contexto político, material e intelectual contemporáneo.

La presunta vinculación entre bellas artes y civilización no era por tanto un argumento novedoso en 1790. Ni siquiera lo fue a la hora de aproximarse a la Antigüedad, pues como acabamos de ver este periodo fue un espacio privilegiado en el siglo XVIII para exponer dicha relación. Por tanto, las Observaciones artísticas de Bosarte y su integración en la valoración de las naciones antiguas no abrieron un horizonte nuevo, sino que más bien aprovecharon caminos ya existentes. Pero no solo cabría ver esta obra como una mera manifestación de la consideración cultural de las bellas artes durante la Ilustración, sino que ayudó a proyectarla pues al plantearla en un escenario de notable entidad literaria y social, viéndose refrendada además por la imprenta (desde la publicación de las conferencias a la de los ejercicios o de noticias en prensa). Aunque el ambicioso proyecto del arquitecto Ventura Rodríguez para la biblioteca de los Reales Estudios no se llegase a realizar, las crónicas revelan que, integrada en uno de los conjuntos monumentales más notables de Madrid como era San Isidro, la biblioteca era grande y aparente, decorada con bustos de griegos y romanos intercalados con una serie de retratos de sabios españoles y alguna que otra autoridad política como Floridablanca. ${ }^{45} \mathrm{Si}$ el escenario aporta contenido a la consideración de lo representado por parte de su audiencia, en este caso parece claro en qué sentido lo hizo. Las bellas artes demostraban poder contar con otros espacios de prestancia más allá de los académicos propios (la Academia de San Fernando estaba instalada desde 1774 en el palacio de Goyeneche de la calle Alcalá) para definir su sentido cultural frente al público. Y eso que faltaban todavía unos treinta años para que el Museo del Prado abriese sus puertas.

\section{Las Observaciones: su autor y sus contenidos}

El perfil de Isidoro Bosarte y la orientación de algunos contenidos de las Observaciones creo que también son relevantes para entender el posible significado de esta publicación en el panorama literario de la Ilustración española, y más específicamente en el de la artística. Bosarte fue un

\footnotetext{
${ }^{42}$ Rollin, 1776a: I, lib. I, cap. III-V.

${ }^{43}$ Rollin, 1776b: I, 114.

${ }^{44}$ Denina, 1793-1795: I, XV-XVII.

${ }^{45} \mathrm{AHN}$, Consejos, 11281-42. En 1788 se le pagaron 640 reales a Francisco Folch de Cardona por un retrato de Floridablanca para la biblioteca. AHN, Jesuitas, 744-1.
} 
asistente y colaborador tipo de la cátedra de historia literaria. En 1790 cumplió 43 años y ya contaba con una trayectoria intelectual tras de sí. Nacido en Baeza y gozando una educación superior, entre 1768 y 1775 fue "pasante" del oidor Antonio de Robles-Vives (cuñado de Floridablanca) en Granada, Madrid y Valladolid. Tras una década como secretario del conde de Aguilar, embajador español en Turín y luego en Viena, volvió a España junto a su protector. Se instaló en Madrid en 1785 a la búsqueda de una colocación vinculada con sus aptitudes y aspiraciones literarias que habían ido cristalizando en esos años. No gozando "de patrimonio ni de otra renta alguna", la necesidad de encontrar una ocupación se hizo todavía más urgente tras la muerte del conde en $1786 .{ }^{46}$

Precisamente en ese año, Bosarte se dio a conocer en el ámbito cultural español con la publicación de la Disertación sobre los monumentos antiguos pertenecientes a las nobles artes de la pintura, escultura y arquitectura que se hallan en la ciudad de Barcelona. Este trabajo, que como su propio nombre indica también se centró en las obras artísticas de la Antigüedad, gozó de cierta difusión y reconocimiento. ${ }^{47}$ Poco después, Bosarte se ocupó del periódico Gabinete de Lectura Española (1787-1793), que publicó en cada uno de sus seis números un extenso discurso sobre diversos temas considerados instructivos, incluyéndose entre ellos las bellas artes. En sus páginas se imprimieron reflexiones sobre la educación, textos de escritores clásicos como Cervantes o Saavedra Fajardo, así como dos artículos dedicados respectivamente a la pintura tras su "restauración" en el siglo XV y al origen de la arquitectura gótica. Es interesante destacar que Miguel de Manuel se atribuyó en cierto momento el impulso del Gabinete. ${ }^{48}$ De hecho, en el verano de 1788 Manuel y Trigueros presentaron la propuesta de impresión de una Gaceta literaria de Madrid. Aunque finalmente no se aprobó, uno de los objetivos de este periódico era informar sobre el pasado y el presente de las bellas artes. De dichos contenidos se ocuparía Bosarte. ${ }^{49}$ Estas noticias confirman el decisivo papel que jugó Miguel de Manuel en su carrera durante este periodo.

La documentación pone de manifiesto que Bosarte quiso promocionarse a través de la biblioteca y la cátedra de historia literaria de los Reales Estudios. Cuando Manuel fue ascendido a bibliotecario primero en 1788 por el fallecimiento de Francisco Messeguer y se convocó su antigua plaza de bibliotecario segundo, Bosarte se presentó a ella. Fue el escritor sevillano Cándido María Trigueros quien consiguió este puesto, pero Bosarte, "clérigo de prima", logró incorporarse a la biblioteca. Diría que incluso antes de 1788, colaboró con Messeguer y Manuel en la edición del Diccionario castellano con las voces de ciencias y artes y sus correspondientes en las tres lenguas francesa, latina e italiana (1786-1793) de Esteban de Terreros, en especial en las cédulas italianas. Su trabajo se valoraría de manera positiva y a principios de 1790, gracias a la propuesta de Miguel de Manuel, empezó a ordenar los manuscritos y la denominada "librería vieja" de los Reales Estudios. En un inicio cobró 12 reales diarios, que era un sueldo modesto, si bien a partir de junio de 1791 se le asignaron 6000 anuales. ${ }^{50}$ Por tanto, su asistencia a la cátedra de historia literaria y su lectura de una disertación en 1790 (y de otra en 1791 sobre el origen de la escritura y los materiales sobre los que se empezó a escribir) ${ }^{51}$ tendrían como finalidad consolidarse en los Reales Estudios y, desde ahí, en ámbitos influyentes de la capital. Lo consiguió. El prestigio de la cátedra en sus primeros pasos, su destacada proyección pública, las posibilidades de publicación que le brindó, permitieron a Bosarte obtener un sueldo y consolidar su presencia en la escena madrileña. Todo

${ }^{46} \mathrm{AHN}$, Consejos, 5444-11. Si bien Bosarte es una figura poco conocida, destaquemos las siguientes semblanzas biográficas: Bosarte, 1978: VII-LXX; Salvatierra / Galera, 2004: 221-232, y la entrada relativa a Bosarte a cargo de Jorge Maier en el Diccionario Biográfico Español de la Real Academia de la Historia.

${ }^{47}$ Se dio noticia de su publicación y se resumió su contenido en el Memorial literario, instructivo y curioso de la corte de Madrid, septiembre de 1786: 48-51. Se citó como modelo de estudio en una contestación a una carta de José Cornide sobre el interés de las bellas artes de Hispania: Diario curioso, erudito, económico y comercial, 24 de noviembre de 1786.

${ }^{48}$ AHN, Estado, 3242-7. Pedro Estala, otro personaje estrechamente vinculado con la biblioteca de los Reales Estudios, fue el responsable del texto del último tomo (1793) del Gabinete: una versión inédita de La República Literaria de Saavedra Fajardo. Arenas, 2003: 199-211. La relación entre el Gabinete y dicha biblioteca parece clara.

49 Aguilar, 1969.

${ }^{50}$ AHN, Consejos, 5443-13 y 5444-11; Jesuitas, 744-1.

${ }^{51}$ Exercicios, 1791: 1-5. 
ello le abrió las puertas de la secretaría de la Real Academia de Bellas Artes de San Fernando en enero de 1792, un puesto relevante en el organigrama cultural de la España carolina y bien pagado. ${ }^{52}$

Queda claro que Bosarte se movió y buscó su promoción en los círculos literarios. Desde que tenemos constancia de su actividad, quien fuera autor del Viage artístico a varios pueblos de Espa$\tilde{n} a(1804)$ se interesó por las bellas artes y es probable que tuviera cierta habilidad (e instrucción) en el dibujo [fig. 2]. No obstante, su carrera y sus pretensiones se encaminaron en otra dirección. Esto supone una diferencia con otras figuras destacadas de la crítica y la historiografía artística española de la Ilustración como Antonio Ponz e incluso Ceán Bermúdez, que sí tuvieron una amplia formación artística de carácter práctico al inicio de sus trayectorias e intentaron - en especial en el caso de Ponz- dedicarse a ellas. ${ }^{53}$ En 1789 Bosarte afirmó con claridad que "su ocupación [es] la literatura". ${ }^{54}$ Desde Viena, intentó conseguir un puesto como arabista a través de José de Viera y Miguel Casiri. ${ }^{55}$ De vuelta a España, se movió para sustituir a Francisco Javier de Garma en el Archivo de la Corona de Aragón en Barcelona (de ahí seguramente su publicación sobre las antigüedades romanas de esta ciudad) ${ }^{56}$ No logró ninguno de estos puestos. Si bien durante los primeros años de su segunda etapa en España no abandonó sus inquietudes arabistas y filológicas, las bellas artes centraron gran parte de sus principales aportaciones eruditas. Puede comprobarse en la Disertación (1786), el Gabinete (1787 y 1788) y las mismas Observaciones (1790-1791). Al menos desde un punto de vista laboral, no fue una elección desacertada porque le acabó proporcionando la ocupación más destacada de su trayectoria al permitirle entrar en la Academia de San Fernando.

Las bellas artes, por tanto, eran un ámbito en el que poder labrarse un nombre en la República de las Letras e incluso hallar una ocupación a través de la pluma. Es más, aun no siendo un fenómeno nuevo, ${ }^{57}$ Bosarte evidencia cómo los escritores y los eruditos, sin una formación necesariamente extensa en la práctica artística, tenían un creciente peso en su literatura. Las bellas artes y sus textos se incorporaban cada vez con mayores conexiones a la esfera cultural y literaria. Así lo revelan las Observaciones: por el contexto para el que fueron realizadas, por su lectura pública, pero también por el perfil de su autor $\mathrm{y}$, como anunciaba líneas arriba, por algunos de sus planteamientos.

No es este el lugar para analizar con detalle los contenidos de las Observaciones, pero me gustaría detenerme en algunos puntos relacionados con el marco en el que fueron presentadas. Contienen múltiples referencias a que fueron leídas (t. I, p. 10, 13, 39) y a los Reales Estudios (I, $105 ; \mathrm{IV}, 64)$. En relación a este último punto, tal vez la cita más interesante sea al monetario de la biblioteca y a los trabajos que sobre esta colección estaba realizando Cándido María Trigueros (IV, 98-99). La formación literaria de su auditorio se hace patente cuando, por ejemplo, Bosarte señaló que no debía detenerse en desgranar las costumbres de los griegos (I, 67) o comentar la reciente edición (1788) de los Comentarios de la pintura de Felipe de Guevara (II, 34-35) porque quienes le escuchaban ya estaban bien informados sobre ello. Incluyó muchas sentencias de autores clásicos, a veces fragmentos de citas o textos en latín (I, 85, 110-111; II, 54; III, 55-59) y discutió largo $\mathrm{y}$ tendido sobre la interpretación de diversos términos aparecidos en las fuentes antiguas (III, $23 \mathrm{y}$ ss.). Las críticas a la traducción de Plinio a cargo de García de la Huerta son constantes, algunas hasta hirientes (I, 128 y ss.). Lo cierto es que la aproximación de Bosarte a las artes griegas en las Observaciones fue eminentemente filológica, basada ante todo en los textos de Vitruvio para la arquitectura y de Plinio para la escultura y la pintura. De todas las obras clásicas, aunque fuesen

\footnotetext{
${ }^{52}$ Fue secretario hasta su fallecimiento en abril de 1807. Distribucion, 1832: 57. Me parece interesante que en 1798, tras la muerte de Manuel, Bosarte se presentó para la plaza de bibliotecario primero de los Reales Estudios, mejor pagada que la secretaría de San Fernando. AHN, Consejos, 5444-11.

53 Crespo, 2020: 242-246.

${ }^{54}$ AHN, Consejos, 5443-13.

${ }^{55}$ Páz-Sánchez, 2016.

${ }^{56}$ AHN, Consejos, 5444-11.

${ }^{57}$ Portús, 1999.
} 


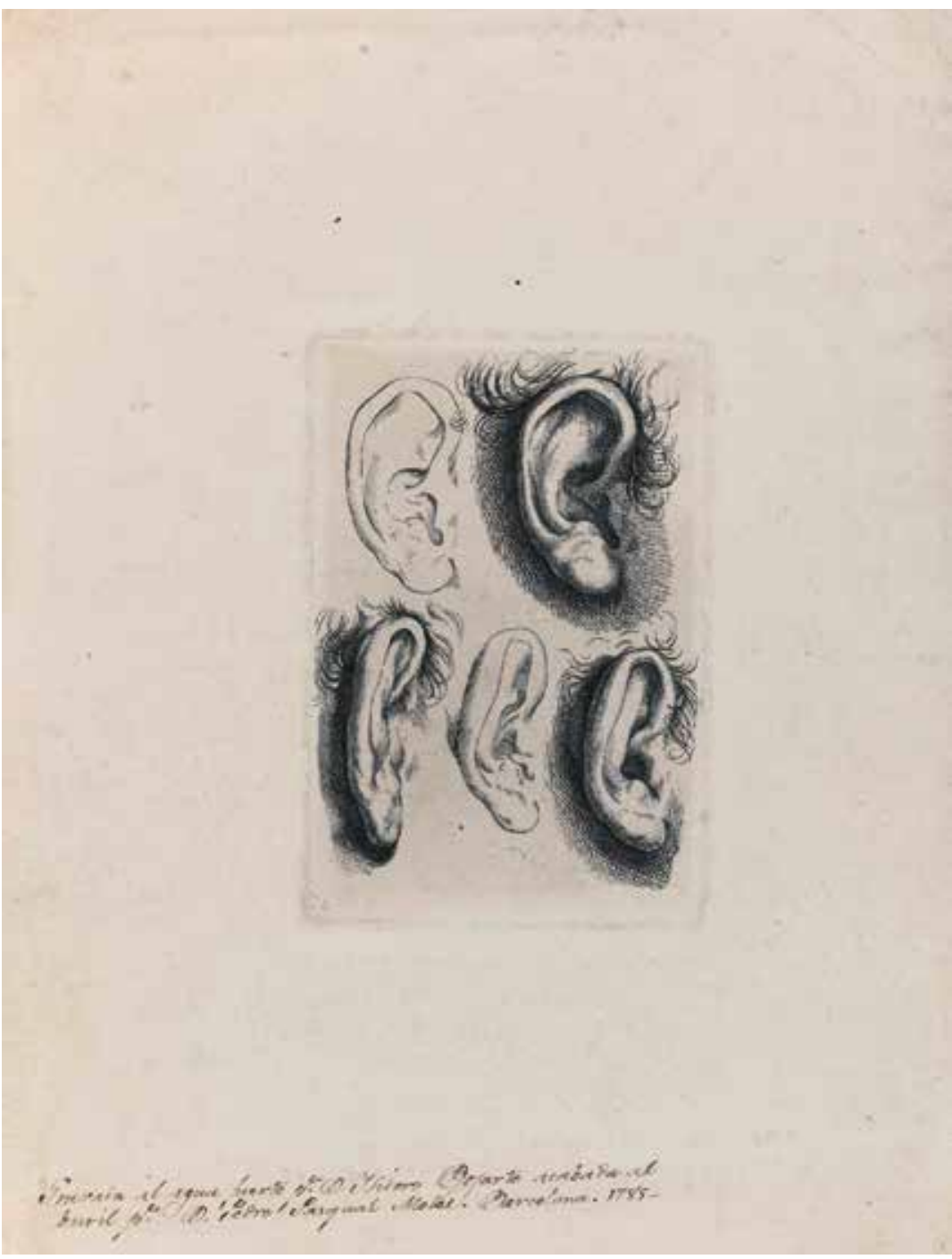

Fig. 2. Isidoro Bosarte, Estudios de orejas, [1785]. Con la siguiente anotación: "Gravada al aguafuerte por D. Isidro Bosarte acabada al buril por D. Pedro Pascual Moles Barcelona 1785". Biblioteca Nacional de España.

copias, que podían verse en Madrid solo hizo referencia a "un jabalí de mano griega que está en el Museo de antigüedades" del duque de Medinacelli (I, 67). Más allá de su evidente dependencia de la bibliografía continental sobre Egipto, afirmó que su conocimiento sobre su arte se debía a los grabados de antigüedades y a lo que había visto en los gabinetes (IV, 12). Destacó la conocida como Tabla de Isis (o Tabla isiaca), "el monumento más curioso de la antigüedad que se ha traído a Europa" y que había podido admirar en Turín (IV, 63 y ss.).

La concepción de la evolución de las artes de la Antigüedad expuesta en las Observaciones estuvo en consonancia con los postulados defendidos en la cátedra de historia literaria y, en líneas generales, en el mundo académico de la España carolina. La vindicación de la inventiva de los egipcios casa con la de Juan Andrés en los Orígenes. También está en la línea de interés por las aportaciones culturales egipcias que encontramos en las disertaciones de Baltasar Félix Miñano y José Cornide. ${ }^{58}$ En cuanto a los griegos, ya vimos que su ejemplaridad era un argumento am-

58 Andrés, 1784-1806: I, 30-33; Exercicios, 1790: 51 y 59. Junto a su aproximación al arte medieval, la visión del arte egipcio de Bosarte es de los pocos aspectos de su rica literatura artística que ha merecido un análisis sólido por parte de los estudiosos actuales: Calatrava, 1992. 
pliamente compartido que, por descontado, impregnó todas las disertaciones de la cátedra. Martín José Ordoqui afirmó que sus bellas letras proporcionaban modelos "de buena imitación" para los escritores actuales. ${ }^{59}$ Bosarte no fue menos y elogió los principios estéticos que los artistas griegos habrían seguido en sus obras. Al hablar de las esculturas de Fidias sentenció que nadie fue más allá "de los antiguos griegos" (I, 45). Solo Rafael, si no hubiese muerto joven, pudiera haber alcanzado el nivel de algunos de los grandes pintores helénicos (II, 66). Los órdenes arquitectónicos griegos no eran gratuitos o fruto del capricho, sino una elevada invención poética que partía de la naturaleza más perfecta (III, 92). Haciéndose eco de principios que, como los anteriores, estaban extendidos en el pensamiento neoclásico, Bosarte afirmó que la excelencia helénica se debió a que sus artistas habían estudiado e imitado la naturaleza modélicamente. Defendió el dibujo de línea y contorno en el que afirmó habían destacado los griegos, así como la "simplicidad y buenas proporciones" de sus obras $(I, 63,85)$. Hasta manifestó su preferencia por el buril respecto al aguafuerte (IV, 35-37). De hecho, contrapuso el aprendizaje de los artistas plásticos griegos, basado según él en el diseño de contornos, al de los actuales, que pasaban a dibujar de manera muy temprana no con líneas sino con claroscuros y sombreados, "plumeando" o "pintando de lápiz" (II, 15 y ss.). Precisamente, en esta diferencia en su formación radicaba para Bosarte una de las causas de las mayores perfecciones alcanzadas por los artistas antiguos. Es lógico por tanto que abogase por la belleza ideal, "de que ahora se habla tanto y se escribe tanto" (I, 152), frente a dar la espalda a la naturaleza, como presuntamente habían hecho los artistas medievales (II, 32), o imitarla sin más, sin expresar su posible perfección, siguiendo a ciertos pintores modernos naturalistas (II, 16, 8991). Denunció de igual modo el olvido de las correctas reglas de la arquitectura y el mal uso de los órdenes (III, 90); los adornos excesivos e impropios en edificios y retablos (III, 53) - si bien se distanció expresamente de los rigoristas o "los críticos más severos" (III, 104)-, las cornisas onduladas, los retablos de más de un cuerpo y todo aquello de rompía con la euritmia (III, 109-112). Estas advertencias no eran gratuitas, puesto que Bosarte partió de una idea habitual en las academias de las Luces - diría que hasta fundacional- como era la creencia de que las artes vivían un periodo de decadencia. Así las cosas, la ejemplaridad griega no solo era una cuestión erudita.

Algunas de las reflexiones de las Observaciones, sobre todo aquellas que tenían que ver con cuestiones estéticas o de la formación del artista, podrían tener sentido pleno ante un auditorio profesional, pero no necesariamente. Bosarte insistió en que los literatos debían poder analizar de manera adecuada las producciones artísticas, arremetiendo ya al principio de su primera conferencia contra quienes debían suspender "vergonzosamente el juicio de las bellas artes" o refugiarse en comentarios insustanciales $(I, 19)$. Definiéndolas como "una pura parte de la gloria del talento humano" (II, 30), el individuo de cultura debía estar capacitado para valorarlas. Es más, consideró que los literatos disfrutaban de una privilegiada posición puesto que las bellas artes y las bellas letras compartían principios y categorías (I, 14 y 21). De ahí que utilizase en muchas ocasiones referencias a la literatura para explicar el estilo de un artista o conceptos estéticos genéricos (I, 41, 115; III, 29, 68), llegando a afirmar que "si en las artes os llegáis a explicar cómo literatos, os explicaréis bien" (I, 42). Incluso para ilustrar la presunta decadencia de las artes plásticas desde el siglo XVII, su abandono de las formas sencillas y majestuosas por posiciones forzadas y cargadas, Bosarte recurrió al influjo del teatro coetáneo, "al aire teatral", al "garbo teatresco" que según él había pasado del escenario a la tela y al mármol (I, 82 y ss.).

Precisamente, uno de los argumentos vertebradores de su disertación fue la definición de las bellas artes como un acto de invención poética, es decir, similar al proceso de creación literaria. Siguiendo a Aristóteles, definió poesía como "el arte imitar la naturaleza con figuras de expresión" (I, 24). Si a su entender era fácil mostrar que las artes plásticas transformaban poéticamente la naturaleza, consideró que también lo hacía la arquitectura (I, 25 y ss; II, 2). Afirmó que "el hombre no es arquitecto hasta que sea científico y poeta" (III, 8) y definió, recordémoslo, los órdenes arquitectónicos canónicos como un exquisito hallazgo poético. Esto hacía que los literatos o quienes entendían los recursos de la poesía pudiesen juzgar, como poco, el aspecto más determinante

${ }^{59}$ Exercicios, 1790: 34 y 48. 
de las artes (I, 23). De hecho, siempre según Bosarte, las limitaciones de los artistas egipcios se remitían a que su civilización no había cultivado la "poesía natural" (IV, 132). Por el contrario, la aplicación de las "luces de la poesía" explicaba algunas de las grandes aportaciones de los artistas griegos (I, 107, 154; II, 65; III, 71) y de los modernos. Cabe citar aquí la extensa y original descripción de El Escorial incluida en la primera lección. Nuestro autor explicó los principales rasgos de esta admirada obra (ubicación, disposición, forma, decoración) como inspirada expresión de su destino, elogiando "toda la poesía con que está hecha" (I, 29-38). Un botón de muestra: encargando Felipe II a Juan Bautista de Toledo la construcción de un mausoleo, Bosarte afirmó que el arquitecto decidió erigirlo a una jornada de Madrid para recordar la caducidad de la vida, "que es de un día"

Las Observaciones de Bosarte manifiestan que la integración de las artes en la llamada civilización, entre las disciplinas consideradas por las Luces "emanación del talento humano", signo del presunto desarrollo cultural de una comunidad, marcó no solo quienes podían -e incluso debían- referirse a ellas y los públicos y los contextos en los que hacerlo. También podía determinar, como acabamos de ver, la definición de su naturaleza y el modo cómo debían ser analizadas. $\mathrm{Al}$ abordar el periodo egipcio, Bosarte anotó su interés preferente en detenerse en las aportaciones a las artes de esta "nación", porque eran las invenciones "las que deciden el progreso del entendimiento" (IV, 69), las que permitían trazar el amplio fresco del desarrollo del conocimiento de la humanidad. Recordemos que la historia literaria promovida por Manuel o Trigueros siempre tuvo ese anhelo universal. Y no solo: partiendo de una misma concepción del pasado como un todo parcelable de manera precisa y en el que se alternaban episodios de plenitud y de decadencia, Bosarte se detuvo en las causas que motivaban unos y otros. De hecho, las categorías que utilizó eran deudoras del ámbito literario. Algo lógico porque las bellas artes, al definirse como una expresión de civilización se debían explicar en diálogo con los principios que la Ilustración aplicaba a otros aspectos culturales que consideró de enjundia. Así, Bosarte afirmó que la perfección alcanzada por los griegos en las artes se debió sobre todo a la formación de sus artistas (ya lo apunté) y a ciertas costumbres como participar desnudos en las competiciones atléticas y en las de "hermosura", lo que permitía al artista helénico un estudio privilegiado del cuerpo humano (I, 63-82). Rechazó por tanto la posible influencia de la constitución política griega que había lanzado Winckelmann en la Historia del Arte de la Antigüedad (1764) y que fue tan admirada como contestada por su potencial revolucionario. Como no podía ser de otro modo, el absolutismo dificultó la recepción de esta idea en la España de las Luces. Sin ir más lejos, otras disertaciones públicas leídas en la biblioteca de los Reales Estudios también se apartaron de esta concesión a la democracia griega ${ }^{60}$ Desde un mismo espíritu moderado, Andrés negó la relación entre "la libertad y las letras", arremetiendo contra el argumento de que en las "monarquías se envilecen los ingenios y no pueden elevarse, y que al contrario en las repúblicas adquieren los talentos, juntamente con la libertad, mayor elevación". ${ }^{61}$ Según Andrés, la República de las Letras necesitaba la libertad literaria pero no la política. Por ello atribuyó el presunto esplendor de la cultura helénica —incluidas las bellas artes - a un complejo y diverso cúmulo de motivos, entre ellos la instrucción y ciertos hábitos sociales.

Las Observaciones, por tanto, nos conducen a un punto clave. Revelan que la plena integración de las bellas artes en el canon cultural de la Ilustración tuvo consecuencias muy destacadas para estas disciplinas. La tradicional defensa de su carácter liberal se redimensionó en unas nuevas coordenadas con múltiples proyecciones. Entre otras, se redefinieron los debates en los que las bellas artes podían o debían participar, quienes podían abordarlos y el público al que estaban destinados.

${ }^{60}$ Exercicios, 1790: 74: Sobre el extendido silencio en las Luces españolas en torno la libertad para explicar la perfección de las bellas artes: Crespo, 2012: 297-304 y 2016: 139-147.

${ }^{61}$ Andrés, 1784-1806: I, 53. 


\section{BIBLIOGRAFÍA}

Aguilar Piñal, Francisco (1969): “Trigueros y su proyecto de una Gaceta Literaria de Madrid”. En: Anales del Instituto de Estudios Madrileños, IV, pp. 233-240.

Aristófanes, (1794): El Pluto. Comedia de Aristófanes traducida del griego en verso castellano, con un discurso preliminar sobre la comedia antigua y moderna, por don Pedro Estala... Madrid: Sancha.

Andrés, Juan (1784-1806): Origen, progresos y estado actual de toda la literatura. Madrid: Sancha.

Bosarte, Isidoro (1790-1791): Observaciones sobre las bellas artes entre los antiguos hasta la conquista de Grecia por los romanos. Madrid: Benito Cano.

Bosarte, Isidoro (1978). Viaje artístico a varios pueblos de España. Madrid: Turner. Prólogo de Alfonso Pérez Sánchez.

Calatrava, Juan (1992): "Isidoro Bosarte y la nueva egiptomanía del final del siglo XVIII: las Observaciones sobre las bellas artes entre los antiguos (1791)". En: Cuadernos de Arte de la Universidad de Granada, XXIII, pp. 373-382.

Cornide, José (1791): Ensayo sobre el origen, progresos y estado de la Historia Natural entre los antiguos anteriores a Plinio. Madrid: Benito Cano.

Crespo Delgado, Daniel (2012): Un viaje para la Ilustración. El Viaje de España (1772-1794) de Antonio Ponz. Madrid: Marcial Pons.

Crespo Delgado, Daniel (2016): "Escribir la historia de la arquitectura en la España de las Luces". En: Cuadernos dieciochistas, 17, pp. 115-147.

Crespo Delgado, Daniel (2020): “Justa melancolía. La historia del arte durante la Ilustración española”. En: David García López y Elena Santiago Páez (dirs.). Ceán Bermúdez y la historiografia de las bellas artes. Gijón: Trea, IFESXVIII, pp. 227-248.

Crespo Delgado, Daniel / Domenge Mesquida, Joan (2013): “Jovellanos: la Ilustración, las artes y Mallorca”. En: Jovellanos: Memorias histórico-artísticas de arquitectura. Madrid: Akal, 13-144.

Denina, Carlo (1793-1795): Historia política y literaria de Grecia... Traducida en castellano por D. Joseph Navia y Bolaño. Madrid: Pantaleón Aznar.

Distribucion de los premios concedidos por el Rey Nuestro señor a los discípulos de las tres nobles artes. Hecha por la Real Academia de San Fernando en la junta pública de 24 de septiembre de 1808. Madrid: Ibarra.

Exercicios públicos de historia literaria que tendrán en los Estudios Reales de Madrid... (1790). Madrid: Benito Cano.

Exercicios públicos de historia literaria que han de tenerse en la biblioteca de los Estudios Reales de Madrid... (1791). Madrid: Benito Cano.

Maier Allende, Jorge, "Isidoro Bosarte”, Diccionario Biográfico Español, Real Academia de la Historia. En: http://dbe. rah.es/biografias/18254/isidoro-bosarte [consultado el 2-1-2021].

Miguel Alonso, Aurora (1992): La biblioteca de los Reales Estudios de San Isidro. Madrid: Universidad Complutense de Madrid.

Páz-Sánchez, Manuel de (2016): "Un orientalista en Viena. Las cartas inéditas (1781-1783) de Isidoro M. Bosarte a José de Viera y Clavijo". En: ACL Revista literaria, 6, pp. -52.

Portús Pérez, Javier (1999): Pintura y pensamiento en la España de Lope de Vega. Madrid: Nerea.

Rollin, Charles (1776a): Historia de las artes y ciencias. Madrid: Blas Román.

Rollin, Charles (1776b): Historia de las artes y ciencias de los antiguos. Madrid: Blas Román.

Romero Recio, Mirella (2004): "La historia antigua en la enseñanza: los ejercicios públicos de historia literaria en los Reales Estudios de San Isidro (1790-1791)". En: Cuadernos del Instituto Antonio de Nebrija, 7, pp. 235-262.

Salvatierra Cuenca, Vicente / Galera Andreu, Pedro (2004): Universitarios giennenses en la historia. Apuntes biográficos. Jaén: Universidad de Jaén.

Santiáñez, Nil (2007): "Literature as discipline. The first chair of literary history in Spain (1786-1802)". En: Dieciocho, 30.2, pp. 315-337.

Scandellari, Simonetta (2007): "El concepto de progreso en el pensamiento de Juan Andrés". En: Cuadernos dieciochistas, 7, pp. 17-46.

Simón Díaz, José (1992). Historia del Colegio Imperial de Madrid. Madrid: CSIC, $2^{\mathrm{a}}$ ed.

Trigueros, Cándido María (1790?): Discurso sobre el estudio metódico de la historia literaria, para servir de introducción a los primeros Exercico Públicos de ella.... Madrid: Benito Cano.

Urzainqui, Inmaculada (1987): "El concepto de historia literaria en el siglo XVIII". En: Homenaje a Álvaro Galmés de Fuentes. Madrid: Gredos, Universidad de Oviedo, t.III, pp. 565-593.

Viñao, Antonio (1995): "Por un análisis socio-cultural de la élite intelectual y académica: los profesores y bibliotecarios de los Reales Estudios de San Isidro (1770-1808)”. En: Bulletin Hispanique, 97-1, pp. 299-315.

Fecha de recepción: 18-II-2021

Fecha de aceptación: 16-III-2021 